\title{
Stability of Fe-oxide nanoparticles coated with natural organic matter (NOM) under relevant environmental conditions
}

\author{
L. Chekli *, **, S. Phuntsho*, L.D. Tijing*, J. Zhou*, Jong-Ho Kim*** and H.K. Shon**** \\ * School of Civil and Environmental Engineering, University of Technology, Sydney (UTS), Post Box 129, \\ Broadway, NSW 2007, Australia. \\ ** CRC CARE, PO Box 486, Salisbury, SA 5106, Australia. \\ ***School of Applied Chemical Engineering \& The Research Institute for Catalysis, Chonnam National University, \\ Gwangju 500-757, Korea
}

\begin{abstract}
Manufactured nanoparticles (MNPs) are increasingly released into the environment and thus research on their fate and behaviour in complex environmental samples is urgently needed. The fate of MNPs in the aquatic environment will mainly depend on the physico-chemical characteristics of the medium. The presence and concentration of natural organic matter (NOM) will play a significant role on the stability of MNPs by either decreasing or exacerbating the aggregation phenomenon. In this study, we firstly investigated the effect of NOM concentration on the aggregation behaviour of manufactured Fe-oxide nanoparticles. Then, the stability of the coated nanoparticles was assessed under relevant environmental conditions. Flow Field-Flow Fractionation (FIFFF), an emerging method which is gaining popularity in the field of nanotechnology, has been employed and results have been compared with another size-measurement technique to provide increased confidence in the outcomes. Results showed enhanced stability when the nanoparticles are coated with NOM due to electrosteric stabilisation. However, the presence of divalent cations, even at low concentration (i.e. less than $1 \mathrm{mM}$ ) was found to induce aggregation of NOM-coated nanoparticles via bridging mechanisms between $\mathrm{NOM}$ and $\mathrm{Ca}^{2+}$.
\end{abstract}

Keywords: Fe-oxide, natural organic matter, nanoparticles, surface coating, stability, aggregation.

\section{Introduction}

There is a critical need for information on the fate of manufactured nanoparticles (MNPs) once they are released into the environment in order to support risk assessments and policy development. After entering an environmental compartment, the fate of the MNPs will depend on their stability (e.g. aggregation, sedimentation) and transformation (e.g. oxidation, reduction, dissolution) (Lowry et al., 2012). Aggregation and sedimentation have been proved to be the main processes affecting their behaviour in aquatic systems and they are mainly the results of the combined effect of $\mathrm{pH}$, ionic strength, salt composition and the presence and concentration of organic matter (Phenrat et al., 2007; Christian et al., 2008). Natural surface coating of NPs by natural organic matter (NOM) has been known to affect their aggregation behaviour; resulting in reduced aggregation through electrosteric stabilisation mechanisms or enhanced aggregation through charge neutralisation and bridging mechanism with divalent cations (Christian et al., 2008).

In this study, we investigated the effect of NOM concentration on the stabilisation of manufactured Fe-oxide nanoparticles. While many studies employed humic acid (HA) as surrogate for NOM (Baalousha et al., 2008; Chekli et al., 2013a), aquatic natural organic matter extracted from the Suwannee River NOM (SRNOM, Florida, USA) was utilised to better mimic environmental sample complexity. In fact, one of our previous studies (Chekli et al., 2013b) showed that SRNOM composition is quite complex and consists of humic substances as well as high molecular weight compounds (i.e. around 20,000 Da) and organic acids having low molecular weight (i.e. around $250 \mathrm{Da}$ ). The stability of the bare and coated nanoparticles was then assessed under environmentally relevant conditions (i.e. different $\mathrm{pH}$ and ionic 
strength). Results from this study were also compared with our previous study (Chekli et al., 2013a) where HA were used as a NOM source instead of SRNOM.

Because of the complexity of MNPs behaviour once subjected to environmental conditions, an approach of multiple characterisation is necessary to ensure accuracy and reliability of the data (Lead and Wilkinson 2006; Domingos et al., 2009). Flow field-flow fractionation (FlFFF) has been chosen in this study as it is well suited to characterise MNPs behaviour under environmental conditions by simply modifying the mobile phase used during characterisation. The results obtained from FIFFF were then compared with those from another size-measurement technique, dynamic light scattering (DLS) to provide a more comprehensive analysis of MNPs.

\section{Material and Methods}

\section{Chemical and reagents}

Commercially available Fe-oxide NPs $\left(\alpha-\mathrm{Fe}_{2} \mathrm{O}_{3}\right.$, average particle size $30 \mathrm{~nm}$, BET 50$245 \mathrm{~m}^{2} / \mathrm{g}, 20$ wt.\% dispersed in water at $\left.\mathrm{pH} 4\right), \mathrm{NaCl}$ and $\mathrm{CaCl}_{2}$ (99.99\% purity) were all supplied by Sigma-Aldrich Australia. SRNOM was obtained from the International Humic Substances Society (IHSS, St. Paul, USA) and was employed as a surrogate NOM.

\section{Sample preparation}

The methodology for sample preparation of NOM-coated Fe-oxide NPs can be found in our previous study (Chekli et al., 2013a). In brief, $10 \mathrm{~mL}$ of concentrated Fe-oxide NPs (i.e. $2 \mathrm{~g} / \mathrm{L}$ ) were mixed with either 1, 2, 4, 10 or $20 \mathrm{~mL}$ of SRNOM (initial concentration of the stock solution: $500 \mathrm{mg} / \mathrm{L}$ ) to obtain five solutions with Fe-oxide NP concentration of $200 \mathrm{mg} / \mathrm{L}$ and SRNOM concentration of 5, 10, 20, 50 and 100 $\mathrm{mg} / \mathrm{L}$.

\section{Flow Field-Flow Fractionation (FlFFF) analysis}

The FlFFF instrument used in this study is described in our previous publication (Chekli et al., 2013a) and the theory and principles of FlFFF can be found elsewhere (Giddings 2000).

The operating conditions used in this study are summarised in Table 1.

Latex beads of $22 \mathrm{~nm}, 58 \mathrm{~nm}, 100 \mathrm{~nm}$ and $410 \mathrm{~nm}$ were used to create calibration curves from which hydrodynamic diameters of the particles were determined.

Table 1 Summary of the different FlFFF operating conditions used in this study.

\begin{tabular}{|c|c|c|c|c|}
\hline & Study & $\begin{array}{c}\text { Channel } \\
\text { Flow } \\
\text { (mL/min) } \\
\end{array}$ & $\begin{array}{c}\text { Cross } \\
\text { Flow } \\
(\mathrm{mL} / \mathrm{min}) \\
\end{array}$ & Mobile phase \\
\hline \multirow{5}{*}{$\begin{array}{c}\text { Effect of } \\
\text { SRNOM } \\
\text { concentration }\end{array}$} & SRNOM alone $(100 \mathrm{mg} / \mathrm{L})$ & \multirow[t]{5}{*}{ (1-2) } & \multirow[b]{2}{*}{0.3} & \multirow{5}{*}{ Ultrapure water at $\mathrm{pH} 4$} \\
\hline & $\begin{array}{c}\text { Fe-oxide NPs alone (200 } \\
\text { mg/L) }\end{array}$ & & & \\
\hline & $\begin{array}{c}\text { SRNOM/Fe-oxide NPs } 5 \\
\text { mgSRNOM/L }\end{array}$ & & \multirow{3}{*}{0.15} & \\
\hline & $\begin{array}{c}\text { SRNOM/Fe-oxide NPs } 50 \\
\text { mgSRNOM/L }\end{array}$ & & & \\
\hline & $\begin{array}{c}\text { SRNOM/Fe-oxide NPs } \\
100 \mathrm{mgSRNOM} / \mathrm{L} \\
\end{array}$ & & & \\
\hline \multirow{2}{*}{$\begin{array}{l}\text { Stability of } \\
\text { SRNOM- }\end{array}$} & $\mathrm{pH} 4$ & \multirow{2}{*}{1} & \multirow{2}{*}{0.15} & Ultrapure water at $\mathrm{pH} 4$ \\
\hline & $\mathrm{pH} 7$ & & & Ultrapure water at $\mathrm{pH} 7$ \\
\hline
\end{tabular}




\begin{tabular}{|c|c|c|}
\hline \multirow{2}{*}{$\begin{array}{l}\text { coated } \mathrm{Fe}- \\
\text { oxide NPs }\end{array}$} & $\mathrm{pH} 7 / 10 \mathrm{mM} \mathrm{NaCl}$ & $10 \mathrm{mM} \mathrm{NaCl}$ at $\mathrm{pH} 7$ \\
\hline & $\mathrm{pH} 7 / 0.5 \mathrm{mM} \mathrm{CaCl}_{2}$ & $0.5 \mathrm{mM} \mathrm{CaCl}_{2}$ at $\mathrm{pH} 7$ \\
\hline
\end{tabular}

\section{DLS analysis}

Details on the DLS instrument used in this study as well as reference to its theory and principles can be found in our previous study (Chekli et al., 2013a). Samples used in DLS experiments were the same as for FlFFF experiments to enable data comparison and ensure accuracy in the data.

\section{Results and Discussion}

Effect of NOM concentration on particle surface charge

Figure 1 shows the zeta potential profiles of Fe-oxide NPs alone $(200 \mathrm{mg} / \mathrm{L})$, SRNOM-coated Fe-oxide NPs at variable SRNOM concentration and SRNOM alone $(100 \mathrm{mg} / \mathrm{L})$ plotted as a function of $\mathrm{pH}$, ranging from 3 to 10 .

At low SRNOM concentrations (i.e. from 5 to $20 \mathrm{mg} / \mathrm{L}$ ), the zeta potential of Feoxide NPs decreases; resulting in the point of zero charge (PZC) occurring at lower $\mathrm{pH}$ values (i.e. from $\mathrm{pH} 7$ for $0 \mathrm{mg} / \mathrm{L}$ SRNOM to $\mathrm{pH} 4$ for $20 \mathrm{mg} / \mathrm{L} \mathrm{SRNOM}$ ). Similar results were obtained in our previous study (Chekli et al., 2013a) where it was found that the shift in the $\mathrm{pH}$ of the $\mathrm{PZC}$ was due to the formation of organic coating from the HA macromolecules on the surface of Fe-oxide NPs causing a change in their surface charge (Zhou et al., 1994). The zeta potential of SRNOM indicates that it is negatively charged over the whole $\mathrm{pH}$ range. In fact, it has been demonstrated that NOM macromolecules carry many negatively-charged functional groups, including carboxylic and phenolic hydroxyl groups (Hajdú et al., 2009; Hu et al., 2010). At higher concentrations (i.e. above $20 \mathrm{mg} / \mathrm{L}$ ), the zeta potential of SRNOM-coated Feoxide NPs was found negative across the whole $\mathrm{pH}$ range tested and is similar to the zeta potential profile of SRNOM alone, which may suggest that SRNOM completely covered the surface of the NPs. Similar observations were reached in our previous studies (Chekli et al., 2013a; Chekli et al., 2013b). At pH values greater than the PZC of the bare Fe-oxide NPs (i.e. above $\mathrm{pH} 7$ ), both the nanoparticles and SRNOM are negatively charged and thus, it is not expected that adsorption of SRNOM occurs as it is known to be mainly due to Coulombic interactions from opposed charged particles. Thus, the observed decrease in zeta potential values is possibly related to the increased SRNOM concentration which brings more negative charges into the solution. 


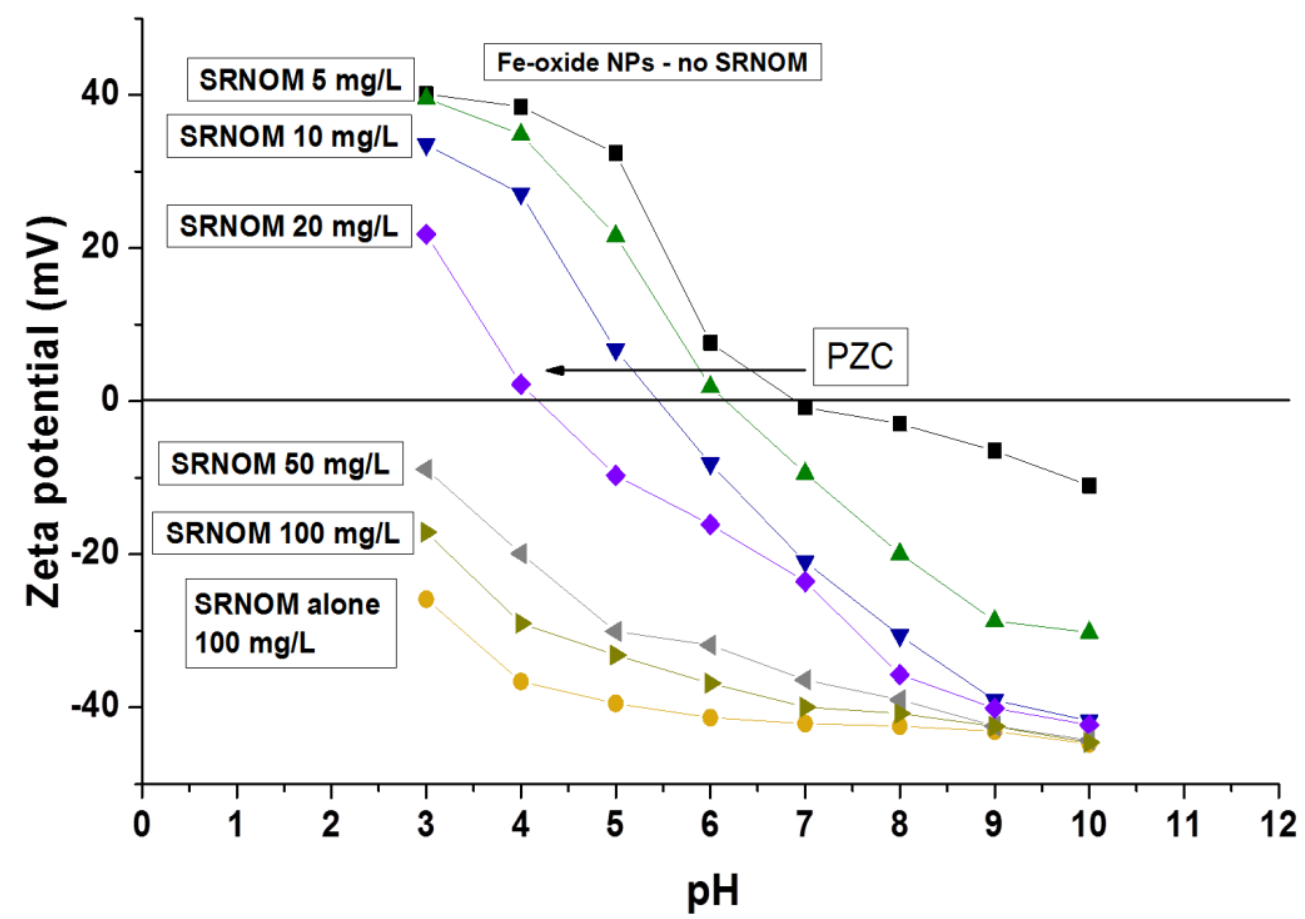

Figure 1 Effect of SRNOM concentration on the zeta potential profile of Fe-oxide NPs as a function of $\mathrm{pH}$.

\section{Effect of NOM concentration on particle aggregation}

The effect of SRNOM concentration on the aggregation of Fe-oxide NPs was investigated by both FIFFF and DLS as shown in Figure 2. Measurements were all carried out at $\mathrm{pH} 4$ as it provides the most favourable conditions for sorption. In fact, at this $\mathrm{pH}, \mathrm{Fe}$-oxide NPs are strongly positively charged whereas SRNOM is still strongly negatively charged (i.e. zeta potential of $+38.5 \mathrm{mV}$ and $-36.6 \mathrm{mV}$ respectively, Figure 1) and many studies have demonstrated that the adsorption of DOM on the surface of metal oxide NPs is mainly governed by Coulombic forces via ligand-exchange reactions (Filius et al., 2000; Chorover and Amistadi 2001; Illés and Tombácz 2004).

At low concentration (i.e. $<20 \mathrm{mgSRNOM} / \mathrm{L}$ ), the adsorption of negatively-charged SRNOM molecules neutralises the positive charges on the surface of Fe-oxide NPs as shown in the zeta potential values decreasing from $+38.5 \mathrm{mV}$ to almost zero (Figure 1). Thus, aggregation takes place as the electrostatic repulsive forces between particles is reducing with increasing SRNOM concentration to reach a peak at 20 $\mathrm{mg} / \mathrm{L}$ where the zeta potential is reduced to almost zero suggesting that no more repulsive forces exist between the particles. In our previous study using HA as a surrogate for NOM, it was also found that $20 \mathrm{mgHA} / \mathrm{L}$ is enough to reduce the zeta potential of Fe-oxide NPs $(200 \mathrm{mg} / \mathrm{L})$ down to zero and thus induce extensive aggregation (Chekli et al., 2013a). Due to the formation of very large aggregates at SRNOM concentrations of 10 and $20 \mathrm{mg} / \mathrm{L}$ (aggregates size above $700 \mathrm{~nm}$ - Figure 2a) which were observed to rapidly sediment at the bottom of the vial, it was not possible to analyse these samples with FlFFF. The FlFFF fractogram (Figure 2b) of the mixture of Fe-oxide NPs with $5 \mathrm{mg} / \mathrm{L}$ of SRNOM shows an apparent shift toward longer retention times indicating the formation of a coating layer of SRNOM around the Fe-oxide NPs. This result differs from the one obtained with HA in our previous 
study (Chekli et al., 2013a). In fact, no change was observed in the size of the Feoxide nanoparticles (from the FlFFF fractograms) when $5 \mathrm{mgHA} / \mathrm{L}$ were introduced in the solution. This was attributed to the fact that the number of coated-particles was too low or the coating layer was too small for the instrument to detect it. In the present study, the addition of $5 \mathrm{mgSRNOM} / \mathrm{L}$ induced a significant change in the size of the nanoparticles (i.e. from $44.16 \mathrm{~nm}$ to $87.88 \mathrm{~nm}$ ). This can be explained by the fact that SRNOM possesses higher molecular weight compounds than HA whereas HA has a greater amount of low-molecular weight components (Chekli et al., 2013b). Our previous study showed that Fe-oxide nanoparticles preferentially adsorbed the higher molecular weight compounds which suggests that the resulting coating layer from SRNOM is larger than the one from HA which may explain the difference in size (Chekli et al., 2013b).

At SRNOM concentrations above $50 \mathrm{mg} / \mathrm{L}$, the surface of the Fe-oxide NPs becomes negatively charged (i.e. Figure 1) providing enough electrostatic repulsive forces between the particles to reduce their aggregation as seen in Figure 2a. An increase in the void peak UV signal can be observed on the FlFFF fractograms of 50 $\mathrm{mg} / \mathrm{L}$ and $100 \mathrm{mg} / \mathrm{L}$ (Figure 2b). This is most likely due to the unadsorbed SRNOM macromolecules which are significantly smaller than the Fe-oxide NPs (i.e. in the order of few nanometres) and were therefore not retained by the applied crossflow and eluted at the beginning of the measurement. When SRNOM concentration was increased to $100 \mathrm{mg} / \mathrm{L}$, both DLS and FlFFF measurements showed a slight increase in the particle size, which is probably due to the formation of larger aggregates as a small fraction of the sample settled on the bottom of the vial. However, this fraction (of larger aggregates) was more significant in the case of HA and this is probably due to the fact that SRNOM not only provide electrostatic repulsion but also steric repulsion due its higher composition in higher molecular weight compounds. Moreover, the size of the coated-particles was found larger when SRNOM were employed instead of HA which is presumably related to the higher molecular weight compounds of SRNOM preferentially adsorbed by the Fe-oxide NPs.

Finally, it is clear from the results displayed in Figure 2 that FlFFF presents several advantages over conventional size-measurement techniques (i.e. DLS). In fact, compared to DLS which only measures an average particle size, FIFFF is a fractionation method and separation of the sample according to its polydispersity in terms of size allows accurate determination of the particle size distribution which is very useful for aggregation studies. Besides, as a fractionation method, it can also provide valuable information of the coating itself. For instance, the FlFFF results may be used to assess the concentration of SRNOM adsorbed onto the nanoparticles by comparing the intensity of the UV signal of the void peak on the fractograms of SRNOM alone and SRNOM-coated Fe-oxide NPs. 

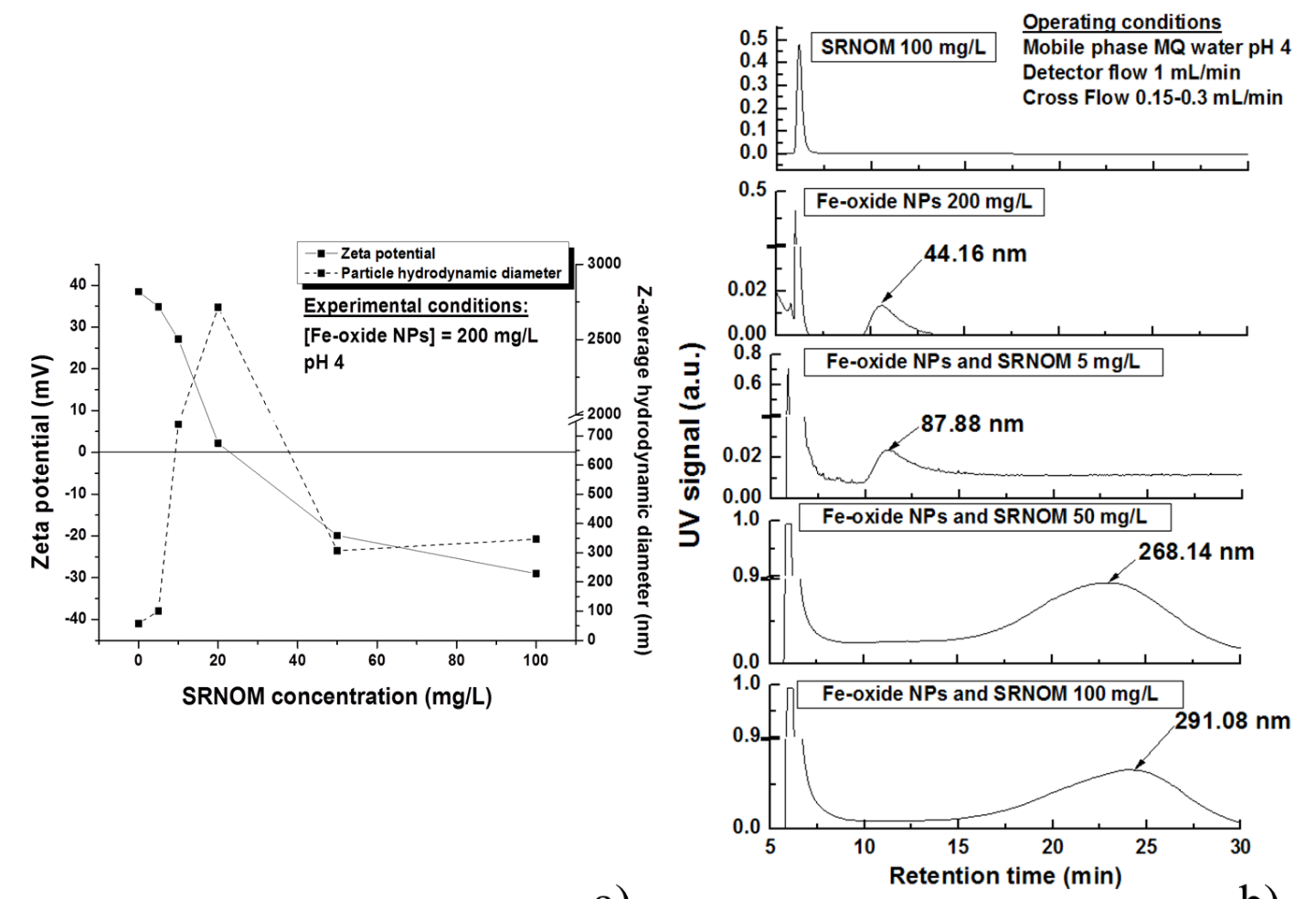

a)

b)

Figure 2 (a) DLS results and (b) FIFFF fractograms of SRNOM-coated Fe-oxide NPs at variable concentrations $(5-100 \mathrm{mg} / \mathrm{L})$.

\section{Stability or SRNOM-coated Fe-oxide NPS under relevant environmental conditions}

The stability of the coated NPs was then investigated under environmentally relevant

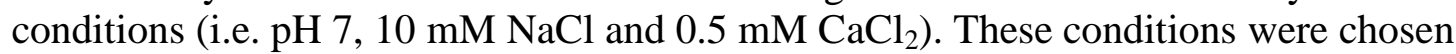
as they represent the typical conditions found in soil and groundwater where ironbased NPs are often used for environmental remediation (Saleh et al., 2008). Figure 3 shows the FIFFF and DLS results of the stability study for Fe-oxide NPs (200 mg/L) coated by SRNOM $(50 \mathrm{mg} / \mathrm{L})$. The size analysis showed relatively good agreement among the two size-measurement techniques although the sizes measured by DLS were larger than those measured by FlFFF. In fact, one of the main limitations of DLS is the strong particle size dependence of the scattering intensity which tends to induce a shift toward larger sizes (Domingos et al., 2009).

The increase in solution $\mathrm{pH}$ (i.e. from $\mathrm{pH} 4$ to $\mathrm{pH}$ 7) did not affect significantly the stability of the SRNOM-coated Fe-oxide NPs (i.e. increase in size of about 15\%) compared with the uncoated NPs. Similar observations were reached when Fe-oxide NPs were coated with HA as an increase of less than $15 \%$ was observed when the solution pH was changed from $\mathrm{pH} 4$ to $\mathrm{pH} 7$ (Chekli et al., 2013a). In the case of bare $\mathrm{Fe}$-oxide NPs, the increase in $\mathrm{pH}$ to $\mathrm{pH} 7$ resulted in extensive aggregation with the formation of large aggregates (i.e. the resulted size was 35 times higher than the original size at $\mathrm{pH} 4$ ). Figure 1 shows that this $\mathrm{pH}$ is close to the PZC of these NPs where many previous studies demonstrated that there are no more repulsive forces between particles promoting the formation of very large aggregates (i.e. up to several micrometres) (Baalousha et al., 2008; Hu et al., 2010). However, when the NPs were coated with SRNOM, a negative surface charge (i.e. $-36.4 \mathrm{mV}$, Figure 1) was formed which prevented Fe-oxide NPs from aggregating because of electrostatic repulsive 
forces that arose between particles. Moreover, the high molecular weight compounds of SRNOM (Chekli et al., 2013b) may also provide steric stabilisation by causing entropically unfavourable conditions when the particles come closer to one another (Tiller and O'Melia 1993; Illés and Tombácz 2004).

The SRNOM-coated Fe-oxide NPs were also found more stable than the uncoated NPs when subjected to an increase in $\mathrm{NaCl}$ concentration to $10 \mathrm{mM}$. In fact, the increase in $\mathrm{NaCl}$ concentration in the sample resulted in the aggregation of uncoated Fe-oxide NPs with an increase in size of about 5 times whereas no aggregation effect was observed when the particles were coated with SRNOM. Our previous study (Chekli et al., 2013a) showed that this ionic strength (i.e. $10 \mathrm{mM} \mathrm{NaCl}$ ) is sufficient to reduce the repulsive forces between particles and thus enhance their aggregation. The stability of the coated NPs at this ionic strength was also demonstrated in previous studies where iron oxide NPs coated with humic acid (HA) were observed to be more stable under high $\mathrm{NaCl}$ concentration due to the electrosteric stabilisation provided by HA macromolecules (Illés and Tombácz 2004; Hajdú et al., 2009; Chekli et al., 2013a).

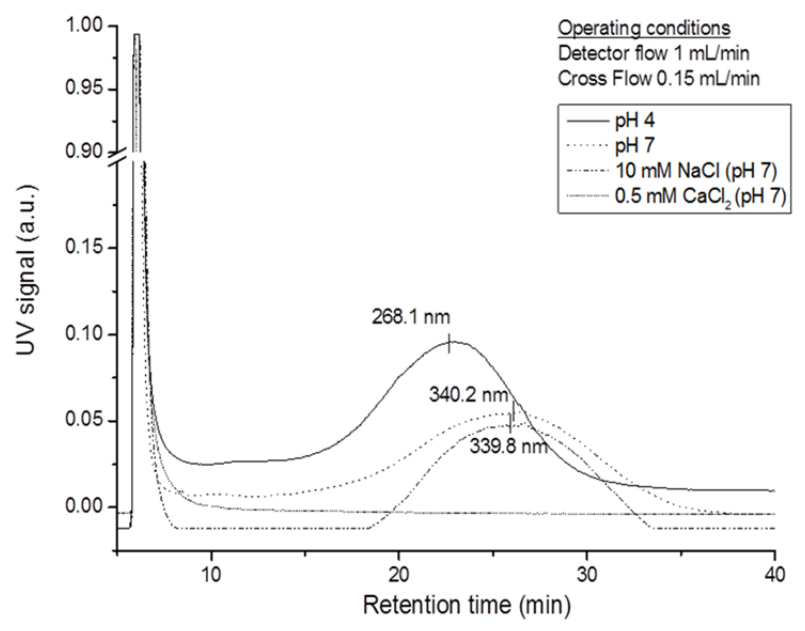

a)

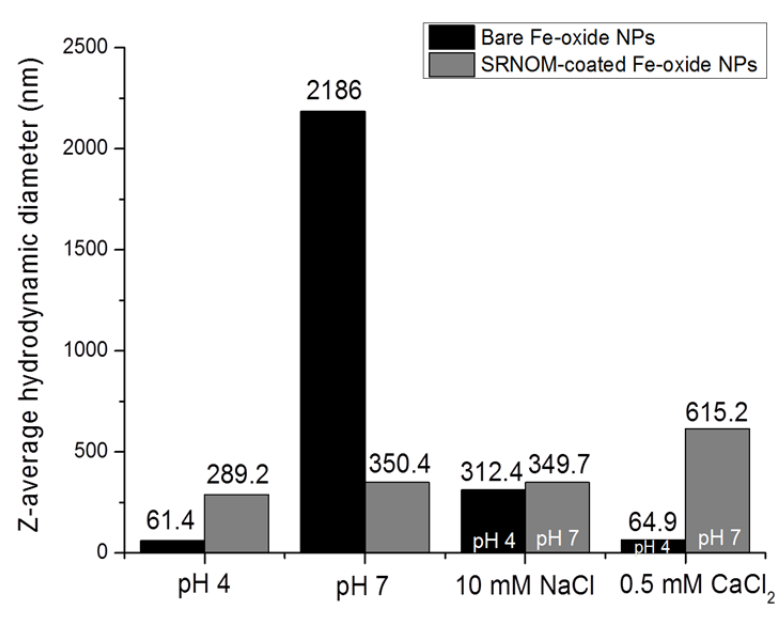

b)

Figure 3 (a) FIFFF fractograms and (b) DLS results of SRNOM-coated Fe-oxide NPs $(50 \mathrm{mg} / \mathrm{L}$ SRNOM and $200 \mathrm{mg} / \mathrm{L} \mathrm{Fe-oxide} \mathrm{NPs)} \mathrm{at} \mathrm{environmentally} \mathrm{relevant} \mathrm{conditions.}$

Finally, the effect of divalent cations (i.e. $\mathrm{Ca}^{2+}$ ) on the stability of both uncoated and coated Fe-oxide NPs was investigated by increasing the concentration of $\mathrm{CaCl}_{2}$ to $0.5 \mathrm{mM}$. Under these conditions, the stability of SRNOM-coated Fe-oxide NPs was more affected than the uncoated NPs resulted in both aggregation (i.e. Figure $3 \mathrm{~b}$ ) and sedimentation (visual observation) of the formed aggregates. However, by comparing the results from our previous study using HA (Chekli et al., 2013a), it can be noted that SRNOM-coated Fe-oxide NPs were less affected by the increase in $\mathrm{Ca}^{2+}$ concentration than HA-coated Fe-oxide NPs. In fact, in the case of HA-coated NPs, the increase in $\mathrm{Ca}^{2+}$ concentration resulted in the formation of aggregates more than five times larger than the original size of the coated particles at $\mathrm{pH} 7$ whereas in the case of SRNOM-coated NPs, the resulted aggregates were less than twice the size of the original coated particles. This result suggests that the higher molecular weight compounds of SRNOM confer more stability to Fe-oxide NPs under high ionic strength conditions than the smaller molecules of HA. The FlFFF fractogram (i.e. Figure 3a) showed no identifiable peak at this ionic strength. These could be 
explained by the larger aggregate size resulting in longer retention time (i.e. longer than the programmed elution time thus not visible in the fractogram) or the applied cross flow forced these larger aggregates to be closer to the FIFFF membrane and thus they could be irreversibly adsorbed onto it. In fact, similar findings were obtained by Dubascoux et al. (2008) where a decrease in the UV signal was observed in the fractograms of samples with higher ionic strength due to the interactions between the FlFFF membrane and the larger aggregates formed under these conditions.

The difference in aggregation behaviour between bare and SRNOM-coated Feoxide NPs at increased concentration of $\mathrm{Ca}^{2+}$ could be explained by the formation of complexes between $\mathrm{Ca}^{2+}$ and the negatively charged groups of SRNOM, which counteracted the negative charge imparted by the SRNOM layer coating on the Feoxide NPs and thus decreased the electrostatic repulsive forces between particles (Chen et al., 2006). In fact, it was demonstrated that the presence of $\mathrm{Ca}^{2+}$ cations may promote the aggregation nanoparticles in the presence of NOM through bridging mechanisms caused by fibrillar attachment (Zhou et al., 1994; Christian et al., 2008). It has also been reported that other alkaline earth metal divalent cations such $\mathrm{Ba}^{2+}$ and $\mathrm{Sr}^{2+}$ could promote iron oxide aggregation at very low concentrations, whereas $\mathrm{Mg}^{2+}$ showed no effect on the stability of nanoparticles, even at high concentrations (Chen et al., 2007).

\section{Conclusions}

The effect of SRNOM concentration on the aggregation behaviour of Fe-oxide NPs as well as the stability of uncoated and SRNOM-coated Fe-oxide NPs has been investigated by combining FIFFF and DLS techniques.

This study showed that the aggregation behaviour of Fe-oxide NPs depends strongly on the presence and concentration of NOM, the solution $\mathrm{pH}$ and ionic strength. Our results suggested that natural surface coating by NOM significantly increases the stability of Fe-oxide NPs under environmental conditions except in the presence of divalent cations where bridging mechanisms can arise between NOM and $\mathrm{Ca}^{2+}$. Results from this study also suggested that the high molecular weight compounds of SRNOM confer a higher stability to Fe-oxide NPs than HA molecules under environmental relevant conditions due to the combination of electrostatic and steric stabilisation effects.

Aggregation and sedimentation of nanoparticles once dispersed in the environment have significant impacts on their transport, reactivity and potential to carry contaminants. Increased stability through NOM coating will likely result in better transport and reactivity while high ionic strength conditions (e.g. commonly encountered in groundwater) may potentially lead to extensive aggregation and sedimentation. Research is still needed to accurately determine the fate and transport of nanoparticles in the environment. This can be achieved by generating more data under realistic environmental conditions and ultimately in real environmental media.

\section{Acknowledgements}

This research was funded by the Cooperative Research Centre for Contamination Assessment and Remediation of the Environment (CRC CARE). 


\section{References}

Baalousha M., Manciulea A., Cumberland S., Kendall K. and Lead J. R. 2008 Aggregation and surface properties of iron oxide nanoparticles: Influence of $\mathrm{pH}$ and natural organic matter. Environmental Toxicology and Chemistry, 27(9), 1875-1882.

Chekli L., Phuntsho S., Roy M., Lombi E., Donner E. and Shon H. K. 2013a Assessing the aggregation behaviour of iron oxide nanoparticles under relevant environmental conditions using a multimethod approach. Water Research, 47(13), 4585-4599.

Chekli L., Phuntsho S., Roy M. and Shon H. K. 2013b Characterisation of Fe-oxide nanoparticles coated with humic acid and Suwannee River natural organic matter. Science of the Total Environment, 461-462,19-27.

Chen K. L., Mylon S. E. and Elimelech M. 2006 Aggregation kinetics of alginate-coated hematite nanoparticles in monovalent and divalent electrolytes. Environmental Science \& Technology, 40(5), 1516-1523.

Chen K. L., Mylon S. E. and Elimelech M. 2007 Enhanced aggregation of alginate-coated iron oxide (hematite) nanoparticles in the presence of calcium, strontium, and barium cations. Langmuir, 23(11), 5920-5928.

Chorover J. and Amistadi M. K. 2001 Reaction of forest floor organic matter at goethite, birnessite and smectite surfaces. Geochimica et Cosmochimica Acta, 65(1), 95-109.

Christian P., Von der Kammer F., Baalousha M. and Hofmann T. 2008 Nanoparticles: structure, properties, preparation and behaviour in environmental media. Ecotoxicology, 17(5), 326-343.

Domingos R. F., Baalousha M. A., Ju-Nam Y., Reid M. M., Tufenkji N., Lead J. R., et al. 2009 Characterizing manufactured nanoparticles in the environment: multimethod determination of particle sizes. Environmental Science \& Technology, 43(19), 7277-7284.

Dubascoux S., Von Der Kammer F., Le Hecho I., Gautier M. P. and Lespes G. 2008 Optimisation of asymmetrical flow field flow fractionation for environmental nanoparticles separation. Journal of Chromatography A, 1206(2), 160-165.

Filius J. D., Lumsdon D. G., Meeussen J. C. L., Hiemstra T. and Van Riemsdijk W. H. 2000 Adsorption of fulvic acid on goethite. Geochimica et Cosmochimica Acta, 64(1), 51-60.

Giddings J. C. (2000). Field flow fractionation handbook Chapter 1: The field-flow fractionation family: Underlying principles, Wiley-interscience.

Hajdú A., Illés E., Tombácz E. and Borbáth I. 2009 Surface charging, polyanionic coating and colloid stability of magnetite nanoparticles. Colloids and Surfaces A: Physicochemical and Engineering Aspects, 347(1-3), 104-108.

Hu J.-D., Zevi Y., Kou X.-M., Xiao J., Wang X.-J. and Jin Y. 2010 Effect of dissolved organic matter on the stability of magnetite nanoparticles under different $\mathrm{pH}$ and ionic strength conditions. Science of the Total Environment, 408(16), 3477-3489.

Illés E. and Tombácz E. 2004 The role of variable surface charge and surface complexation in the adsorption of humic acid on magnetite. Colloids and Surfaces A: Physicochemical and Engineering Aspects, 230(1-3), 99-109.

Lead J. R. and Wilkinson K. J. 2006 Aquatic colloids and nanoparticles: current knowledge and future trends. Environmental Chemistry, 3(3), 159-171.

Lowry G. V., Gregory K. B., Apte S. C. and Lead J. R. 2012 Transformations of nanomaterials in the environment. Environmental Science \& Technology, 46(13), 6893-6899.

Phenrat T., Saleh N., Sirk K., Tilton R. D. and Lowry G. V. 2007 Aggregation and sedimentation of aqueous nanoscale zerovalent iron dispersions. Environmental Science \& Technology, 41(1), 284-290.

Saleh N., Kim H. J., Phenrat T., Matyjaszewski K., Tilton R. D. and Lowry G. V. 2008 Ionic strength and composition affect the mobility of surface-modified $\mathrm{Fe} 0$ nanoparticles in water-saturated sand columns. Environmental Science \& Technology, 42(9), 3349-3355.

Tiller C. L. and O'Melia C. R. 1993 Natural organic matter and colloidal stability: Models and measurements. Colloids and Surfaces A: Physicochemical and Engineering Aspects, 73, 89102.

Zhou J. L., Rowland S., Fauzi R., Mantoura C. and Braven J. 1994 The formation of humic coatings on mineral particles under simulated estuarine conditions-A mechanistic study. Water Research, 28(3), 571-579. 